\title{
Conference on the Legacy of Russian Women Scientists: Dedicated to the Centenary of the Great Russian Revolution
}

The conference "Centenary of the Great Russian Revolution: Women's Faces in Russian Science-The Legacy" took place on 7-8 November 2017 in Moscow, Russia, and was dedicated to the 100th anniversary of the legal equality of the genders in Russia. It was organized by both the Institute for the History of Science and Technology (IHST) of the Russian Academy of Sciences, and the Archive of the Russian Academy of Sciences. There were over 60 historians of science not only from Russia, but also from Ukraine and Belarus. The working language of the conference was Russian.

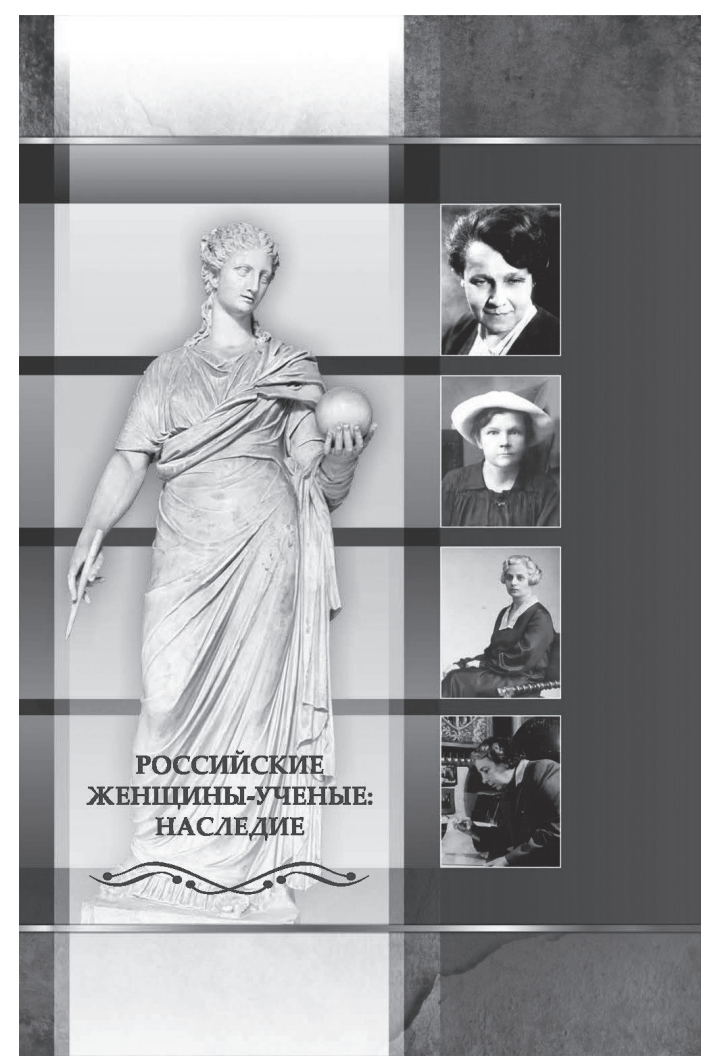

The revolutionary events of 1917 brought many large and small changes in the everyday life of the Russian state, Russian society, and individual citizens of the country. One of the most fundamental changes was the recognition of the legal equality of women. Russian women not only received the right to participate fully in the political and public life of the country, but equal rights to education and access to previously unattainable professions for them. One of these was the profession of a scientist. The conference discussed the results that the recognition of the legal equality of women has brought to Russian science and Russian women scientists. 
The main aim of the conference was to identify and analyse the scientific legacy of Russian women scientists from the first part of the 19th century to the beginning of the 21 st century, as well as their documented legacy in archives, libraries, and museums.

The conference participants examined the biographies of women of different generations who had devoted their lives to scientific work: those who lived, worked and achieved recognition in the period of the Russian Empire; surviving during a period of revolutionary changes at the age of national consciousness; the already formed but still young professionals who worked most of their lives under the new political conventions; and, finally, those who were born either before or after 1917 and did not live under legal discrimination. The participants' papers were dedicated to women scientists who work in various scientific fields. Besides, particular attention was paid to women who, for various reasons, had to move outside of Russia. The academic careers of Russian women scientists abroad and their contribution to the development of science were covered in the presentations as well.

The conference included six sessions, three on each day. Below we will give a brief overview of the most interesting papers, in our opinion, from every session.

During the first session, the speakers gave presentations on the first women scientists of the Russian Empire. Olga Valkova's (IHST, Russian Academy of Sciences, Russia) paper was the result of a comprehensive study on the life and activities of Olga Aleksandrovna Fedchenko (1845-1921), the first woman natural scientist, who was elected as corresponding member of the Imperial Academy of Sciences. The author stressed that Fedchenko was also the first outstanding woman botanist in Russia.

The presentation by Aleksandr Matveychuk (The A. Solzhenitsyn House of Russians Abroad, Russia) was dedicated to Yuliya Vsevolodovna Lermontova (1847-1919), the first Russian female petrochemist. The author managed to eliminate a number of gaps and inaccuracies that have existed up to the present time in researches devoted to the biography of this outstanding scientist. Besides, Matveychuk in his speech paid special attention to Lermontova's experiments on oil distillation.

Another session introduced women's scientific education in the Russian Empire. For example, the presentation 'The organization of the teaching of zoological disciplines at the Moscow Higher Ladies' Courses' by Roman Fando (IHST, 
Russian Academy of Sciences, Russia) was based on interesting archival sources extracted by the author from the collections of the Central State Archive of Moscow. Most of them were introduced in scientific circulation for the first time. Subsequently, many graduates of the Moscow Higher Ladies' Courses became leading specialists in Russia in the various areas of zoology.

The session dedicated to women scientists who were contemporaries of the establishment of legal equality of the genders in Russia featured interesting papers. The presentation by Simon Ilizarov (IHST, Russian Academy of Sciences, Russia), entitled 'Russian women entering the professional field of history of science during its first hail in the 20th century', focused on women who worked at the first research institutions for the history of science. New materials on the life and the work of talented historians of science (O. A. Dobyash-Rozhdestvenskaya, I. I. Lyubimenko, E. Ch. Skrzhinsky, V. F. Gnucheva, S. A. Yanovsky and others) were very interesting. Ilizarov showed that women entering into the community of historians of science in large numbers was directly connected with the establishing of the Institute for the History of Science and Technology within the system of the Academy of Sciences of the USSR.

The paper 'Unrecognized teachers at the Institute of Red Professors in 1937' by Evgeniya Dolgova (Russian State University for the Humanities, Russia) analysed the composition of the academic staff of the Institute of Red Professors by statistics methods on the lists, questionnaires and autobiographies of the teaching staff and administration of the institute. However, the speaker's conclusion that the Institute of Red Professors was not an "engaged ideological instruction" seems not very persuasive and needs more evidence.

Two sessions discussed women scientists born in the USSR. The main focus of the paper by Igor Pechenkin (All-Russian Scientific Research Institute of Mineral Raw Materials, Russia) was on the life and research work of the outstanding Soviet mineralogist Ekaterina Vladimirovna Rozhkova. The author showed the great contribution of E. V. Rozhkova in the solution of important problems of the mineral raw material resources of the USSR. It should be mentioned than Rozhkova was not only a scientist but a brilliant teacher as well, creator of scientific school on applied mineralogy.

In her presentation 'Contribution of E. A. Galkina to the development of national research on marshes', Lyubov Kopyonkina (Tver State University, Russia) explored how the aeronautical method for studying wetlands created by E. A. Galkina was introduced in the research practices. 
The last session committed to Russian women scientists abroad. The paper by Natalia Kolotilova (Moscow State University, Russia) 'The fate of the female students of Ilya Ilyich Mechnikov before and after 1917' explored the important aspect of the history of female medical education abroad. The author focused especially on the first Russian women microbiologists: P. V. Tsiklinskaya, L. M. Horowitz-Vlasova, and M. N. Margulies-Aitova. In addition, the paper gave a fresh look at one of the pages of the history of the famous Pasteur Institute in Paris.

As a result of the conference, the collective monograph Российские женщиныученые: наследие ('Russian Women Scientists: The Legacy') was published. It includes all the papers presented at the conference. The book, consisting of five chapters, systematized chronologically and thematically, is available online at http://www.ihst.ru/content/monografii-2017-g.

In conclusion, it is also worth mentioning that Olga Valkova deserves special thanks for her great work in organizing of the conference.

\section{Elena Sinelnikova Vladimir Sobolev}

S. I. Vavilov Institute for the History of Science and Technology of the Russian Academy of Sciences (IHST RAS), St. Petersburg Branch. 